\title{
Protagonismo da linguagem: textos como agentes
}

\section{Protagonist language: texts as agents}

Izabel Magalhães*

Universidade de Brasília

Brasília - Distrito Federal / Brasil

\begin{abstract}
RESUMO: Este artigo propõe discutir uma concepção social de linguagem em relação ao mundo contemporâneo, conceituando o protagonismo da linguagem e dos textos. A linguagem e os textos possuem uma força agenciadora, que atua por meio de agentes sociais. Textos protagonistas apresentam quatro características: o poder de produzir significados e evocar lembranças; a portabilidade no tempo, no espaço e no contexto; a durabilidade; e os efeitos causais, chamando atenção para determinados aspectos do mundo social e construindo identidades. Discute-se a relação entre linguagem e sociedade, examinando mudanças epistemológicas nos últimos cinquenta anos. A relação entre ideologias linguísticas e mudança discursiva é um pressuposto para a análise de dois textos que abordam a ocupação de escolas no país, em um macrocontexto de uma sociedade capitalista neoliberal.
\end{abstract}

PALAVRAS-CHAVE: protagonismo da linguagem; textos; mudança discursiva; ideologias linguísticas; ocupação de escolas.

ABSTRACT: This paper proposes to discuss a social view of language in relation to the contemporary world, introducing the notion of protagonist language and text. Language and texts have an agentive force that acts through social agents. Protagonist texts present four characteristics: power to produce meanings and activate memories; portability in time, space and context; durability; and causal effects, drawing attention to aspects of the social world and constructing identities. We discuss the relation between language and society, examining epistemological changes over the last fifty years. The relation between language ideologies and discourse change is an assumption for the analysis of two texts about school occupation in Brazil, in a macro context of a neoliberal capitalist society.

KEYWORDS: protagonist language; texts; discourse change; language ideologies; school occupation.

*mizabel@uol.com.br 


\section{Introdução}

Vivemos em um contexto de mudanças: em primeiro lugar, há que destacar as transformações econômicas e culturais da modernidade posterior, com a transição das práticas de produção fordista para um período de acumulação flexível (HARVEY, 2000). A contrapartida cultural resulta em transformações no contexto social, em que se enfatizam mudanças linguísticas e discursivas. Algumas dessas mudanças são: hibridismo nos gêneros discursivos, criação de novos gêneros; estabelecimento de cadeias de gêneros, sinalizando mudanças discursivas; textos multimodais e cadeias intertextuais (FAIRCLOUGH, 2001a [2016], 2003; KRESS, 2010).

Registram-se, também, mudanças na pesquisa da linguagem, principalmente na pesquisa sociolinguística sobre o multilinguismo (MARTIN-JONES; GARDNER, 2012). Na esteira dessas mudanças, notase um movimento epistemológico para uma abordagem crítica e etnográfica, sob a influência da relação com a ciência social crítica. Assim, na pesquisa da linguagem, tem-se uma perspectiva crítica e pós-estruturalista.

Há, portanto, um olhar atento, que examina:

[...] mudanças sociais, culturais e linguísticas introduzidas pela globalização, pelos fluxos populacionais transformacionais, pelo advento das novas tecnologias da comunicação, por mudanças na paisagem política e econômica de diferentes regiões do mundo (MARTIN-JONES; GARDNER, 2012, p. 1). ${ }^{1}$

Ao observarmos o cenário brasileiro, notamos certamente uma avassaladora influência da língua inglesa no cotidiano da população, no uso de expressões pela classe abastada e na apontada necessidade de estudar inglês para criar um blog de negócios, para a venda de produtos artesanais, roupas e outros produtos (RODRIGUES JÚNIOR, 2015).

O objetivo deste artigo é debater uma concepção social da linguagem em relação ao mundo contemporâneo de superdiversidade, examinando a força e o protagonismo da linguagem e de agentes sociais em face de abusos de poder. O que queremos dizer com protagonismo da linguagem? Propomos que a linguagem tem uma força agenciadora, energética, atuando por meio de agentes sociais, falantes e escreventes (AUSTIN, 1962; BARTON; PAPEN, 2010; FAIRCLOUGH, 2010; MAGALHÃES, 2013).

\footnotetext{
${ }^{1}$ As traduções, neste artigo, são de nossa autoria.
} 


\section{Linguagem e sociedade}

A relação entre linguagem e sociedade é debatida por diversos estudiosos. No livro Discourse in late modernity, Chouliaraki e Fairclough (1999) sugerem que há uma relação entre linguagem como discurso e práticas sociais. Por práticas, eles entendem "modos habituais ligados a um tempo e a um local particulares, em que as pessoas aplicam recursos (materiais ou simbólicos) para agirem juntas no mundo" (CHOULIARAKI; FAIRCLOUGH, 1999, p. 21). O pressuposto desses autores, vale lembrar, é que "a vida (natural e social) é um 'sistema aberto', em que qualquer evento é governado por 'mecanismos' operativos simultâneos (ou 'poderes gerativos')" (CHOULIARAKI; FAIRCLOUGH, 1999, p. 19; COLLIER, 1994; BHASKAR, 1986). Para Chouliaraki e Fairclough (1999), baseados em Harvey (1996), há uma relação dialética entre discurso e outras dimensões das práticas, que se pode visualizar desta forma:

\section{FIGURA 1 - Discurso e prática social (CHOULIARAKI; FAIRCLOUGH, 1999)}

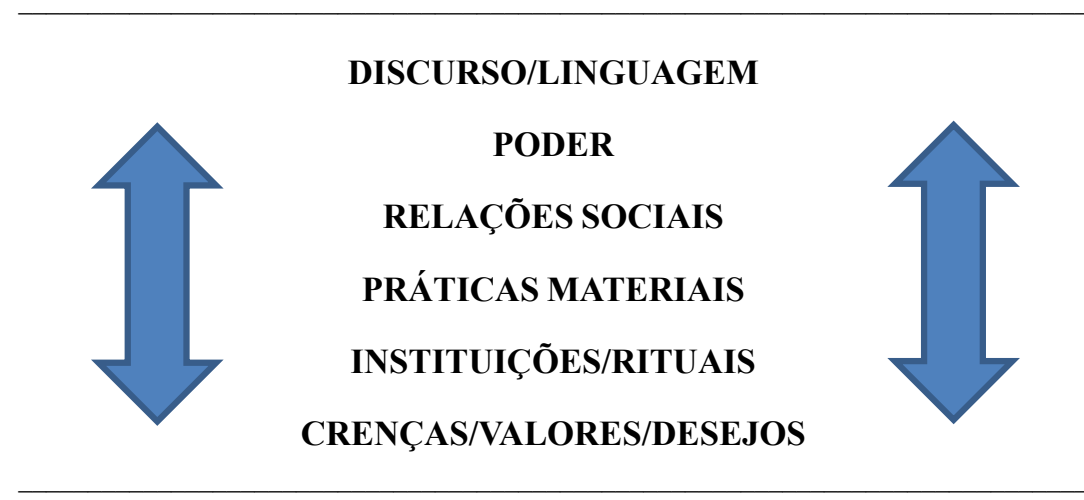

Há uma interiorização de cada dimensão nas outras, então, o discurso interioriza poder, relações sociais, práticas materiais, instituições e seus rituais, crenças, valores e desejos. Portanto, é fundamental dar atenção a esse ponto ao tratar das mudanças sociais contemporâneas.

Em relação ao processo de globalização na relação entre linguagem e sociedade, Fairclough (2006, p. 3) faz o seguinte comentário:

Aqui há duas formulações gerais dos conjuntos complexos de mudanças que são amplamente referidos como "globalização": "um processo (ou conjunto de processos) que incorpora uma transformação na 
organização espacial das relações e transformações sociais [...] gerando fluxos transcontinentais ou inter-regionais e redes de atividade, interação, e o exercício de poder" (HELD et al., 1999, p. 16); a "conectividade complexa $[\ldots]$ a rede de interconexões e interdependências em desenvolvimento rápido e adensamento persistente, que caracteriza a vida social moderna" (TOMLINSON, 1999, p. 2). Os "fluxos", as "redes" e as "interconexões" geralmente são considerados de caráter muito diverso, e incluem, por exemplo: fluxos de mercadorias e dinheiro, e redes financeiras e comerciais internacionais, no campo econômico; redes intergovernamentais, e interdependências, interações e interconexões entre agências internacionais como as Nações Unidas, o Fundo Monetário Internacional e a Organização Mundial de Comércio e agências governamentais em escalas nacional e regional; a mobilidade de pessoas como migrantes, turistas ou membros de organizações comerciais ou governamentais; fluxos de imagens, representações e interações mediante mídias e tecnologias de comunicação contemporâneas; e assim por diante.

O comentário de Fairclough (2006) esclarece sobre a complexidade das mudanças sociais contemporâneas, apontando o papel da linguagem nos processos de globalização, pois

[...] as redes, conectividades e interações que transpõem fronteiras e limites espaciais incluem crucialmente, e poderíamos dizer dependem de, formas particulares de comunicação (ou o que chamarei gêneros discursivos) que são especializadas em interação transnacional e inter-regional. (FAIRCLOUGH, 2006, p. 3).

Por exemplo, a charge sobre Lula em uma reunião de cúpula internacional (MAGALHÃES, 2010).

Algumas implicações dessas mudanças são: novas concepções sobre o estudo das relações entre linguagem e sociedade, e as realidades heterogêneas, superdiversas da sociedade contemporânea (VERTOVEC, 2007; BLOMMAERT, 2005; PENNYCOOK, 2012, 2001). Os novos estudos "consideram a nova ordem comunicativa e as condições culturais particulares do nosso tempo, ao mesmo tempo em que mantêm uma preocupação central com os processos envolvidos na construção da diferença social e da desigualdade social" (MARTIN-JONES, GARDNER, 2012, p. 1). 


\section{Mudanças epistemológicas}

Nos últimos cinquenta anos, sociolinguistas, linguistas antropológicos e analistas do discurso opõem-se à concepção de linguagem como sistema gramatical e defendem, ao contrário, a concepção de signos socialmente situados (HYMES, 1972; HALLIDAY, 1978; BAKHTIN, 1979; GUMPERZ, 1982; HELLER, 1995; PENNYCOOK, 2001; RAJAGOPALAN, 2003; FAIRCLOUGH, 2001a, 2003, 2010; BLOMMAERT, 2005; KRESS; VAN LEEUWEN, 1996; VAN DIJK, 2012).

Na Figura 2 apresentamos as abordagens teóricas desses estudiosos, lembrando que há diferenças entre eles. Porém, une-os a perspectiva de estudo social da linguagem.

FIGURA 2 - Linguagem socialmente situada

\begin{tabular}{ll}
\hline INVESTIGADOR(A) & \multicolumn{1}{c}{ ESTUDO } \\
\hline HYMES & ETNOGRAFIA DA COMUNICAÇÃO \\
HALLIDAY & SEMIÓTICA SOCIAL \\
BAKHTIN & DIALOGISMO \\
GUMPERZ & SOCIOLINGUÍSTICA INTERACIONAL \\
HELLER & SOCIOLINGUÍSTICA CRÍTICA \\
RAJAGOPALAN & LINGUÍSTICA CRÍTICA \\
FAIRCLOUGH & TEORIA SOCIAL DO DISCURSO \\
BLOMMAERT & SOCIOLINGUÍSTICA CRÍTICA \\
VAN DIJK & COGNIÇÃO SOCIAL \\
KRESS, VAN LEEUWEN & GRAMÁTICA DO DESIGN VISUAL \\
PENNYCOOK & LINGUÍSTICA APLICADA CRÍTICA \\
\hline
\end{tabular}

Embora o pensamento desses investigadores não seja epistemicamente e nem ontologicamente igual, converge, contudo, para o estudo da linguagem na sociedade, em oposição a abordagens voltadas para a imanência linguística. Nesse sentido, eles representam um avanço significativo em relação às abordagens do estruturalismo e do gerativismo no estudo da linguagem (FAIRCLOUGH, 2001a [2016]). Trataremos aqui apenas da diferença entre Blommaert (2005) e Fairclough (2001a, 2003). 
A crítica de Blommaert (2005) a Fairclough (2001a) é problemática, pois deixa de considerar a extensa obra deste, baseando-se praticamente na obra de 2001. Ambos discutem o conceito de ideologia, com uma diferença: Fairclough (2001a) propõe o conceito de "mudança discursiva" na contemporaneidade, enquanto Blommaert (2005) restringe-se à discussão de desigualdades sociais em relação a situações da Bélgica e da África. Com relação ao cenário de escalas do neocapitalismo, em que os textos podem transitar da escala global à nacional, regional e local, e no sentido contrário, não se trata de contribuição inovadora de Blommaert (2005), encontrandose em Fairclough (2001b [2012]), a propósito de extensa citação do trabalho de Jessop (2000).

Por exemplo, em alguns pontos da análise de Blommaert (2005), quando ele examina a carta dirigida a ele de uma menina africana de dezesseis anos, de Dar es Salam, na Tanzânia, o comentário que faz contribui para reforçar a desigualdade social. Diz Blommaert (2005, p. 80):

Vitória mobiliza o máximo de recursos de status a seu alcance, o melhor inglês possível (escola), o código de status e a mobilidade social ascendente na Tanzânia. E é nesse sentido que os erros tornam-se importantes. Transplantada a uma situação equivalente na Europa, e aplicando as ordens de indexicalidade que sejam válidas lá, o código usado por Vitória não funciona para indexar status e prestígio de elite.

Para entender o comentário de Blommaert (2005, p. 80), é preciso citar a definição que ele apresenta à página 73 da mesma obra:

[Ordens de indexicalidade são] significados sistemicamente reproduzidos, estratificados, frequentemente denominados "normas" ou "regras" linguísticas específicas (exemplo, a variedade "padrão", de prestígio, a maneira "usual" de ter uma conversa com meus amigos e amigas, etc.).

No caso da carta da menina africana, cabe indagar se a afirmação de que o uso linguístico "não funciona" para "indexar status e prestígio de elite" não significaria uma posição marcadamente ideológica.

O próprio Blommaert (2005) reconhece que as "ordens de indexicalidade" são muito próximas às "ordens do discurso", um conceito de Foucault (1996) apropriado por Fairclough (2001 [2016], 2010). De acordo com Fairclough (2010 [1995], p. 28): 
[Ordens do discurso são] domínios de hegemonia e luta hegemônica (ideológica) em instituições como a educação, como também na formação social mais ampla.

Note que o conceito de Fairclough refere-se a "luta hegemônica", o que faz uma grande diferença em relação ao conceito de Blommaert. Falar sobre ordem do discurso é falar sobre hegemonias e contra-hegemonias organizadas hierarquicamente em seus elementos, principalmente relacionados a discursos, gêneros e estilos (FAIRCLOUGH, 2003), tornando o conceito de Fairclough mais forte para debater nossa concepção de protagonismo da linguagem.

\section{Ideologias linguísticas}

Na década de 1990, com o pós-estruturalismo e o pós-modernismo, houve uma preocupação com o estudo de ideologias linguísticas (MARTINJONES; GARDNER, 2012). Nesse tipo de pesquisa, estabelecia-se relação entre unidades linguísticas e unidades sociais (GAL; IRVINE, 1995; SCHIEFFELIN; WOOLARD; KROSKRITY, 1998; MOITA LOPES, 2013).

\subsection{0 caso da língua afrikaans}

O desenvolvimento do afrikaans, uma língua formada com base no holandês e em determinantes africanos e asiáticos, na África do Sul, associada à hegemonia branca, é um caso emblemático de ideologia linguística. (ROBERGE, 1990). Segundo Roberge (1990), o que foi escrito sobre o afrikaans não passa de uma ideologia linguística. Há quatro problemas na análise histórica do afrikaans:

a) Considerar a língua "descendente direta e linear do holandês", pois houve mescla dialetal entre o holandês, o francês e o alemão (ROBERGE, 1990, p. 135);

b) A mescla foi contida na comunidade europeia;

c) $\mathrm{O}$ afrikaans de negros e indígenas sugere uma ruptura radical na transmissão linguística. Ao lado do sistema europeu havia sistemas emergentes entre negros e indígenas no Cabo;

d) Dizer que as influências de línguas não europeias (khoikhoi, crioulo português e malaio) limitaram-se ao léxico e aspectos da periferia gramatical. As variedades negras foram consideradas "desenvolvimentos separados" (ROBERGE, 1990, p. 136). 
Resumindo a discussão, para Roberge (1990, p. 136): "Desconsiderar a religião civil e a filosofia social na avaliação dessa ideologia é desconsiderar o fator mais importante". Dessa forma, a análise de uma situação linguística pode ser direcionada por uma posição ideológica, nesse caso seria válido falar de um racismo linguístico.

\subsection{O caso dos dialetos sociais no Brasil}

O debate sobre os dialetos sociais é outro exemplo de ideologia linguística, pois é atravessado por noções ligadas à preocupação com o ensino da norma padrão. Há todo um temor histórico em relação às variedades não prestigiadas. Parece que a opressão linguística instaurada pelo Marquês de Pombal no país ainda está impregnada na sociedade. Basta falar de variação linguística para despertar um clamor pelo ensino da gramática portuguesa, encobrindo o fato de sermos uma sociedade plurilíngue e multicultural. De acordo com Faraco (2007, p. 42):

[...] temos de reconhecer que estamos muito atrasados na construção de uma pedagogia da variação linguística. Parece que não sabemos, de fato, o que fazer com a variação linguística na escola. E o que temos feito é seguramente bastante inadequado.

A razão para isso está na defesa da norma padrão, que, na verdade, é uma ideologia linguística, pois a língua falada no Brasil é resultado de inúmeras influências e de um processo de crioulização não reconhecido por gramáticos e nem mesmo por sociolinguistas. Como diz Bagno (2013, p. 337):

A realidade linguística do português brasileiro é radicalmente polarizada. Temos no topo da hierarquia social uma norma urbana de prestígio, que se inspira na tradição escrita literária, que tenta preservar os traços de um português clássico, idioma criado artificialmente por gramáticos e literatos renascentistas, marcados por uma tentativa de aproximar ao máximo o português do latim. Embaixo, temos uma infinidade de variedades desprestigiadas, rurais, mas também cada vez mais urbanas, empregadas pela retumbante maioria da nossa população.

Retornando a Faraco (2007), cabe perguntar: por que não sabemos o que fazer com a variação linguística na escola? A resposta é simples: embora haja tentativas de ir contra a "tradição escrita literária", para usar a expressão de Bagno (2013, p. 337), a elite econômica, empresarial e cultural do país, 
aderindo à ideologia linguística de aproximação do português ao latim, a língua do império romano, reage agressivamente à ideia do processo de crioulização, logo exigindo o retorno à tradição literária e ao ensino da gramática da norma padrão. Só para dar um exemplo, a tentativa de discussão da variação linguística em um livro didático adotado pelo Ministério da Educação sofreu fortes críticas de um comentarista de uma cadeia de TV em rede nacional, e que foram aceitas e reproduzidas por diversos segmentos da sociedade.

\section{Protagonismo da linguagem}

Esse é o contexto sócio-histórico em que propomos debater o protagonismo da linguagem, uma realidade social que oculta o fato de que o português não deriva diretamente do latim, mas do galego, esse sim derivado do latim; o galego foi uma língua românica que se desenvolveu na Galícia, região de Portugal. Outro fato que permanece oculto é o processo de crioulização do português do Brasil, sob a influência de línguas africanas, principalmente as línguas do grupo banto (BAGNO, 2013). Nesse contexto social dominado por arraigadas ideologias linguísticas, pelo racismo (MARTINS, 2011) e por ideologias de gênero (MAGALHÃES, 2003, 2009), é preciso falar do protagonismo da linguagem.

\subsection{Mudança discursiva}

Apoiando-se no conceito de hegemonia de Gramsci (1971), Fairclough (2001a , 2010) discute a luta hegemônica (ideológica). Para Fairclough (2010), há uma relação entre discurso e hegemonia, que pode ser resumida em dois pontos:

a) Naturalização de ideologias

[...] a prática hegemônica e a luta hegemônica, em grande medida, tomam a forma de prática discursiva, na interação falada e escrita. [...] $\mathrm{O}$ conceito de hegemonia implica o desenvolvimento, em vários domínios da sociedade civil (por exemplo, no trabalho, na educação, nas atividades de lazer), de práticas que naturalizam relações e ideologias específicas, práticas que são em grande parte discursivas (FAIRCLOUGH, 2010, p. 129).

As convenções discursivas incorporam ideologias (crenças, conhecimentos, posições e relações entre agentes sociais); por exemplo, nas relações entre docentes e discentes, entre produtores e leitores de jornais e revistas, nas relações assimétricas de gênero. 
b) Hegemonia cultural do discurso

O segundo ponto é a hegemonia cultural do discurso, que existe, por exemplo, na discussão sobre a variedade linguística e a norma padrão. Para Fairclough (2001a, p. 126-127):

Por um lado, precisamos entender os processos de mudança como ocorrem nos eventos discursivos. Por outro lado, precisamos de uma orientação relativa à maneira como os processos de rearticulação afetam as ordens do discurso.

A maneira como falamos pode indicar uma ruptura com o passado, desde que haja uma rearticulação e mudança na hierarquia de gêneros discursivos, discursos e estilos na ordem do discurso. Nesse sentido, cabe dizer que há protagonismo da linguagem e de outros modos comunicativos.

Baseando-se em Smith (1990), Barton (2009, p. 38) refere-se à mediação textual do mundo, em que "os textos fazem parte da cola da vida social". Nessa mesma página do trabalho de Barton, destaca-se o seguinte comentário: "A linguagem e o letramento estão no centro de grande parte da atual mudança social porque a linguagem e o letramento estruturam o conhecimento e viabilizam a comunicação" (BARTON, 2009, p. 38).

Nesse debate, nota-se que determinados agentes sociais agem como "luzes orientadoras" (BARTON; PADMORE, 1991). Esses são mediadores, mentores, corretores e escribas, que atuam nas práticas de linguagem e letramento (BARTON, 2009).

Uma distinção importante existe entre alguém que preenche um formulário para outra pessoa e entre alguém que ensina a pessoa a fazê-lo ela própria. Por exemplo, o preenchimento da declaração de rendimento. Nesse sentido, as pessoas que ensinam a outras, entre as quais se encontram docentes, certamente são luzes que brilham e orientam.

\section{Textos em um mundo em transformação}

Para o protagonismo da linguagem, é fundamental que os textos sejam entendidos em relação às práticas sociais e aos discursos específicos em que se situam, pois é aí que podem atuar. Nessa atuação, a intertextualidade e a interdiscursividade são recursos empregados para direcionar e influenciar nossas ações. Esses são importantes efeitos dos textos (FAIRCLOUGH, 2003). 
Entretanto, ao focar a dinâmica dos discursos num contexto específico, "identificamos diferentes apoiadores" dos textos e de seus propósitos, "o que nos permite ver as pressões que apoiam ou impedem diferentes práticas" (BARTON, 2009, p. 48). Como diz Barton (2009, p. 49): "Textos agem como artefatos culturais - como agentes com apoiadores". Textos também fazem parte de um processo de agenciação em atos de leitura e de escrita (MAGALHÃES, 2013): eles "agem como pessoas, no interesse de pessoas, no lugar de pessoas” (BARTON, 2009, p. 49). Barton estende a atuação de textos às instituições: "[Textos] agem como agentes porque têm defensores. Com frequência, os defensores são instituições, e empregar textos é uma das formas em que as instituições agem como pessoas" (BARTON, 2009, p. 49).

Portanto, trata-se de protagonismo da linguagem e dos textos.

\subsection{Textos protagonistas}

Esses textos apresentam quatro características:

a) o poder de produzir significados e evocar lembranças;

b) a portabilidade no tempo, no espaço e no contexto;

c) a durabilidade;

d) os efeitos causais, chamando atenção para determinados aspectos do mundo social e construindo identidades (WENGER, 1998; BARTON; HAMILTON, 2005; MAGALHÃES; MARTINS; RESENDE, 2017).

Nas próximas seções, serão analisados dois textos para discutir o protagonismo da linguagem.

\section{Texto "Escolas ocupadas: garotas em luta"}

O estado de São Paulo, como o do Paraná, é notório por relações tensas entre o governo e professores(as)/estudantes. Em 2015, escolas de São Paulo foram ocupadas por seus estudantes em reação a um projeto de "reorganização", um eufemismo para mudanças de natureza neoliberal nas escolas (CHIAPELLO; FAIRCLOUGH, 2002). A mesma reação foi constatada no Paraná, em 2016, contra dois projetos do Governo Federal: a Proposta de Emenda à Constituição Federal, denominada PEC do Teto de Gastos, que estabelece um teto na Constituição para despesas no setor público, no período de vinte anos; e o projeto de Reforma do Ensino Médio. A PEC do Teto de Gastos foi aprovada pelo Congresso Nacional 
em dezembro de 2016, enquanto o projeto de Reforma do Ensino Médio encontra-se em debate, com grandes possibilidades de ser efetivamente aprovado. Defendendo uma posição contrária a essas propostas políticas, em 2016 mais de oitocentas escolas do Paraná foram ocupadas. Houve, também, ocupações de escolas em outros estados da Federação e nos institutos federais.

Agora vemos um novo ciclo nacional de ocupações, desta vez contra as medidas de Michel Temer [atual presidente] e centrado nos colégios estaduais do Paraná e nos institutos federais de todo o Brasil, mas com crescimento expressivo de ocupações de escolas em Minas Gerais e no Espírito Santo, além de algumas ocupações ainda em menor número em outros estados (CAMPOS; MEDEIROS; RIBEIRO, 2016, p. 4).

Embora a mídia hegemônica nacional tenha dado pouco destaque a essas manifestações, sabe-se que várias escolas foram desocupadas em ações da polícia a mando de autoridades do governo. Cabe acrescentar que o macrocontexto desses movimentos foi o processo de impedimento de Dilma Rousseff, que foi substituída pelo vice-presidente Michel Temer. Esse episódio político significa uma opção explícita do governo brasileiro pelo neoliberalismo.

Em matéria para a revista Caros Amigos, ${ }^{2}$ a repórter Laís Modelli aborda o protagonismo das secundaristas de algumas das escolas ocupadas em São Paulo, e a questão do machismo e da violência de gênero da PM durante os atos pelo sistema educacional:

Protagonismo das secundaristas levanta a questão do machismo no sistema educacional e a violência de gênero da PM nas manifestações.

NO DIA 9 DE NOVEMBRO, alunos de duas das principais escolas públicas de São Paulo, a Escola Estadual Fernão Dias Paes e a Escola Estadual Diadema, ocuparam as instituições e as trancaram por dentro. A ação ocorreu dias antes do governador Geraldo Alckmin (PSDB) anunciar quem seriam os 74 mil professores e 311 mil alunos afetados com o plano de 'reorganização' das escolas estaduais, em que 94 instituições seriam fechadas. "No dia 8 , meu filho sumiu de casa. Fui na delegacia, fiz o boletim de ocorrência e descobri que ele era um dos alunos que estava ocupando a Fernão Dias. Vim para cá e passei a apoiálo", conta Maria R., uma das mães que fazem parte do Comitê das Mães e Pais em Luta.

${ }^{2}$ MODELLI, L. Garotas em Luta. Caros Amigos, jan. 2016, p. 38. 


\section{Machismo nas escolas}

O movimento evidencia ainda o protagonismo das garotas secundaristas nas ocupações e manifestações. As ocupações nas escolas estão sendo lideradas, na sua maioria, por meninas, que conduzem as assembleias, organizam as tarefas, promovem debates sobre gênero e vão para rua gritar por seus direitos e enfrentar policial na linha de frente. Ao lutarem pelo objetivo central, contra a reorganização, também denunciam o machismo do ambiente escolar e a repressão sexista do Estado ao movimento.

Em maio de 2015, ganhou repercussão o caso de humilhação contra garotas de escola pública de São Paulo nas listas chamadas de Top 10. Cartazes nos corredores dos colégios e listas que circulavam pela internet divulgavam ranking com nome e foto das alunas mais "vadias" de cada instituição. As alunas lésbicas também eram ridicularizadas em listas exclusivas para homossexuais. Cada colégio tinha o seu ranking, que era atualizado semanalmente desde 2014. As meninas que eram expostas deixavam de frequentar as aulas e pelo menos doze delas tentaram suicídio. No mesmo período em que essas listas começaram a circular, em junho de 2014, a Câmara dos Deputados aprovou o Plano Nacional de Educação (PNE), que estabeleceu vinte metas para a educação de base e de nível superior no Brasil a serem alcançadas até 2024. Várias metas do texto original do PNE, contudo, foram rejeitadas pelos deputados no Congresso Nacional. A meta que previa a promoção da igualdade de gênero e discussões sobre diversidade e sexualidade foi uma das diretrizes derrubadas pelo lobby de grupos religiosos conservadores, defendendo que a "ideologia de gênero" nos currículos ameaçaria a família tradicional. "Estava em uma roda de conversa sobre gênero em uma das ocupações e disse aos estudantes o quanto achava bacana eu poder falar disso com eles justamente em um momento em que foi barrado ensinar questões de gênero nas escolas. Essas conversas têm acontecido muito nas ocupações e acho que agora essa garotada vai voltar para as salas de aula com uma outra cabeça em relação ao machismo e gênero, respeitando suas colegas. Em uma dessas rodas tinha até as meninas que estavam naquela lista do Top 10 e pudemos conversar sobre isso", explica a estudante de Letras, Andreza Delgado, 20 anos, que tem apoiado as ocupações desde o início.

O método deste estudo é a Análise de Discurso Textualmente Orientada (ADTO) proposta por Fairclough (2001a). O autor publicou diversos trabalhos em que defende a abordagem, por exemplo, o publicado em 2003. Na perspectiva de Fairclough, a ADTO associa-se a uma teoria crítica, denominada Análise de Discurso Crítica (ADC). No país, há um debate relativamente forte sobre a ADC (RAMALHO; RESENDE, 2011; 
MAGALHÃES; MARTINS; RESENDE, 2017). No que se segue, faremos uma análise textual; no entanto, nosso interesse é mais teórico do que metodológico.

Há, no texto, uso frequente de palavras que se opõem, por exemplo: "machismo no sistema educacional" e "garotas em luta".

FIGURA 3 - Relação de oposição na linguagem

\begin{tabular}{ll}
\hline DISCURSO DE VIOLÊNCIA & DISCURSO EMANCIPATÓRIO \\
\hline Machismo no sistema educacional & Garotas em luta \\
Violência de gênero & Protagonismo das secundaristas \\
Machismo nas escolas & Espaços de resistência \\
Machismo do ambiente escolar & Protagonismo das garotas secundaristas \\
Repressão sexista do Estado & Ocupação nas escolas \\
Humilhação de garotas & Escolas ocupadas \\
Top 10 & Contra a reorganização \\
Lobby de grupos religiosos & \\
Ideologia de gênero & \\
Família tradicional & \\
\hline
\end{tabular}

O texto é caracterizado pela relação entre esses dois discursos, e embora haja um grupo maior de significados relacionados ao discurso controlador, autoritário, machista e violento, predomina um movimento textual ligado ao discurso emancipatório (MAGALHÃES, 2009). Um exemplo é a citação da estudante de Letras em discurso direto. O protagonismo da linguagem é reforçado pela oração "meninas que conduzem as assembleias, organizam as tarefas, promovem debates sobre gênero e vão para rua gritar por seus direitos e enfrentar policial na linha de frente", com processos materiais (HALLIDAY, 1994). Essa linguagem poderosa é auxiliada pelas citações diretas da mãe de um aluno e da jovem estudante de Letras, mediando pela intertextualidade a construção de identidades afinadas com a mudança discursiva, em duas gerações de mulheres que se opõem ao retrocesso e ao obscurantismo das autoridades do governo estadual e federal. 


\section{Texto "Primavera secundarista: as ocupações se espalham..."}

\subsection{Resumo ${ }^{3}$}

"A nacionalização da tática das ocupações colocou um desafio aos dispositivos de repressão e aos governos de diferentes estados, que reagem de acordo com certos padrões que parecem se repetir. Em São Paulo, o aprendizado da derrota de 2015 representou para o governo uma sofisticação e um endurecimento do autoritarismo

Ao longo de 2016, da mesma maneira que se expandiram territorialmente, as ocupações também foram abraçadas por diferentes atores do campo da luta pela educação pública, antes mais focados em outras ações, mas que após o sucesso da luta contra a "reorganização" e a mudança na conjuntura nacional - radicalizaram suas táticas, sobretudo as entidades estudantis.

Concomitantemente, a nacionalização da tática das ocupações colocou um desafio aos dispositivos de repressão e aos governos de diferentes estados, que reagem de acordo com certos padrões que parecem se repetir. Em São Paulo, o aprendizado da derrota de 2015 representou para o governo uma sofisticação e um endurecimento do autoritarismo: ao mesmo tempo que faz a 'reorganização' de maneira menos visível, ele investe na organização de grêmios aparelhados como instrumentos de verniz democrático. Quanto à repressão, aposta-se na individualização da perseguição/criminalização de secundaristas (algo que ocorre com grande intensidade também em Goiás) e, sobretudo, na realização das reintegrações de posse pela Polícia Militar sem necessidade de mandado judicial, novidade que vem desde maio, quando, baseando-se em um parecer jurídico pedido pelo então secretário de Segurança Pública, Alexandre de Moraes, à Procuradoria Geral do Estado de São Paulo, o governo passou a se abster de recorrer ao Judiciário. Esse tem sido um dos maiores obstáculos à realização de novas ocupações em São Paulo um padrão repressivo que ainda não alcançou os outros estados.

Em âmbito nacional, a individualização da perseguição/criminalização também parece estar sendo adotada como estratégia central de desmobilização e intimidação: no dia 19 de outubro, o MEC [Ministério da Educação] enviou um ofício às diretorias dos institutos federais para que estas identificassem os estudantes que participam de ocupações. A individualização facilita a repressão por acusações de desacato, danos ao patrimônio, entre outras.

${ }^{3}$ CAMPOS, A. M.; MEDEIROS, J.; RIBEIRO, M. M. Le Monde Diplomatique Brasil, nov. 2016, p. 4. 
Nesse texto, a metáfora "primavera secundarista", que associa o movimento estudantil do Ensino Médio à "primavera árabe", chama atenção para diferentes escalas: global, nacional, local (FAIRCLOUGH, 2012). Essas diferentes escalas direcionam os valores atribuídos à linguagem no processo de luta por mudanças sociais. Os valores podem ser ligados a ideologias linguísticas.

FIGURA 4 - Ideologias linguísticas

\begin{tabular}{ll}
\hline ESCALAS & \multicolumn{1}{c}{ LINGUAGEM } \\
\hline Global & "Primavera secundarista" \\
Nacional & "Nacionalização da tática de ocupações" \\
& "Sofisticação e endurecimento do autoritarismo" \\
& "Estratégia central de desmobilização e intimidação" \\
Local & "Diferentes atores do campo da luta pela educação pública" \\
& "Reorganização de maneira menos visível" \\
& "Organização de grêmios aparelhados" \\
& "Instrumentos de verniz democrático" \\
& "Individualização da perseguição/criminalização" \\
& "Reintegrações de posse pela Polícia Militar sem necessidade \\
& de mandado judicial"
\end{tabular}

O texto apresenta um cenário em continuidade ao texto anterior, sugerindo o que o protagonismo de forças políticas que lutam pelo avanço de mudanças sociais pode ser impedido ou intimidado pelo Estado neoliberal, que impõe a ferro e fogo ("reintegrações de posse pela Polícia Militar sem necessidade de mandado judicial") suas propostas de reforma. As três escalas indicam o poder das forças repressoras, em sintonia com o "espírito do capitalismo" (CHIAPELLO; FAIRCLOUGH, 2002, p. 194). Trata-se, mais especificamente, de uma ordem do discurso com discursos hegemônicos, mas também opostos. Dessa forma, o protagonismo da linguagem e dos textos precisa ser entendido em um cenário macro, bastante complexo, envolvendo diferentes escalas e forças antagônicas.

As relexicalizações no texto apontam novos significados para as palavras: "primavera secundarista", "tática de ocupações", "sofisticação e endurecimento do autoritarismo", "estratégia central de desmobilização e intimidação", "campo da luta pela educação pública", "organização de grêmios aparelhados", "instrumentos de verniz democrático", "individualização da 
perseguição/criminalização". Esses novos significados desenvolvem um estilo de guerrilha no campo da educação, que torna o texto e seus autores agentes que se opõem às autoridades defensoras das reformas neoliberais. Portanto, entendemos que o protagonismo constrói posições opostas no estilo de guerrilha: uma a favor das ocupações e outra a favor das reformas. A primeira é insurgente; já a segunda é extremamente autoritária, precisando de uma "estratégia central de desmobilização e intimidação", de "organização de grêmios aparelhados", de "instrumentos de verniz democrático" e da "individualização da perseguição/criminalização", que podem ser consideradas formas truculentas de enfrentar o movimento estudantil.

\section{Agenciação e identidade}

Há três reformas em discussão aqui: a Medida Provisória (MP) $\mathrm{n}^{\circ}$ 746, de Reforma do Ensino Médio no país, enviada pelo governo de Michel Temer ao Congresso Nacional em 22 de setembro de 2016; a PEC n 241, do Teto de Gastos, que foi renumerada no Senado Federal, passando a ser chamada de PEC no 55 (já aprovada pelo Congresso Nacional); e o projeto Escola sem Partido, em discussão no Congresso. Como diz Roberto Fanklin de Leão, presidente da Confederação Nacional dos Trabalhadores em Educação (CNTE): ${ }^{4}$

Como se nota a olho nu, a agenda do golpe se contrapõe às metas do Plano Nacional de Educação (PNE) não apenas nas questões quantitativas. Querem interferir diretamente na formação dos estudantes, limitando o debate e o conteúdo dos currículos escolares - vide o projeto da Lei da Mordaça (Escola sem Partido), que caminha pari passu com a reforma do ensino médio.

O projeto Escola sem Partido, relexicalizado como Lei da Mordaça, proíbe comentários por docentes em sala de aula a respeito de política e orientação sexual ou de gênero, deixando claro o conservadorismo das reformas. Acrescenta Leão a respeito da Reforma do Ensino Médio (2016, p. 5): "Em síntese, o conteúdo da reforma segue a lógica do mercado, sob a égide das agências multilaterais, com destaque para a cartilha do Banco Mundial".

\footnotetext{
${ }^{4}$ LEÃO, R. F. de. Reforma autoritária e extemporânea do Ensino Médio: trabalhadores em educação resistem. Le Monde Diplomatique Brasil, nov. 2016, p. 5.
} 
Já a forma aligeirada com que se pretende aprovar mais esse expediente neoliberal é ainda pior que a empregada em outras propostas do governo, pois se pauta numa medida provisória. E não há como deixar de questionar esse expediente autoritário, que inviabiliza o amplo e necessário debate social sobre tema da mais alta relevância para a sociedade.

$\mathrm{Na}$ opinião do presidente da CNTE e vice-presidente mundial da Internacional da Educação para a América Latina (IEAL), falta discussão do assunto e, principalmente, diálogo com docentes e estudantes, significando alinhamento com o Banco Mundial e desrespeito pela população brasileira. Nesse contexto, como não dar razão à desobediência civil? Um regime verdadeiramente democrático não deveria precisar de "instrumentos de verniz democrático".

Os textos que analisamos falam de repressão, mas também de um campo de resistência, que vamos discutir em termos do conceito de agenciação: "A agenciação estabelece relação entre as identidades e a ética nas práticas e nos eventos sociais (com suas atividades), nos discursos e textos, nas relações sociais, crenças e histórias pessoais, e no mundo material (objetos, instrumentos e tecnologias)" (MAGALHÃES, 2013, p. 365). Para Block (2012), citando Archer (2007), não há como separar agenciação de estrutura social: "enquanto a estrutura social existe independentemente da agenciação individual, ela não é efetiva como modeladora da agenciação até ser encontrada por indivíduos engajados em atividades" (BLOCK, 2012, p. 54). Block propõe quatro parâmetros para compreender a relação entre agenciação e identidade, e como a agenciação situa-se na "estrutura social e nas práticas cotidianas que, por sua vez, são feitas de interações” (BLOCK, 2012, p. 54):

a) Todos os "atos de agenciação" pertencem a uma "moldura temporalhistórica"; portanto, há restrições à agenciação, com o "reconhecimento de processos sociais além da consciência das pessoas que os vivenciam" (BLOCK, 2012, p. 54);

b) A agenciação é emoldurada culturalmente;

c) Os atos de agenciação reúnem recursos semióticos;

d) A relevância do espaço físico, tanto macro (instituições) quanto micro (salas de aula).

Considerando esses parâmetros, percebe-se que o protagonismo da linguagem e dos textos depende dos atos de agenciação, e não há como 
negar que o poder está do lado das autoridades do governo, com Medidas Provisórias, Projetos de Lei e Propostas de Emenda à Constituição. Esses textos têm efeitos nas escolas e nas salas de aula. Como diz Camilla Croso, coordenadora geral da Campanha Latino-Americana pelo Direito à Educação (Clade) e presidenta da Campanha Mundial pela Educação (CME):

A Medida Provisória (MP) n $n^{\circ} 746$, imposta pelo governo Temer, que reformula o ensino médio da educação brasileira, inscreve-se plenamente nesse contexto amplo de privatização da educação que ocorre na América Latina e no mundo. Em primeiro lugar, porque toma como base, e ao mesmo tempo aprofunda, o desmonte da educação pública e a apropriação de recursos públicos por setores privados em prol do lucro e de uma orientação político-pedagógica da educação alinhada com os interesses de mercado. ${ }^{5}$

Dessa forma, o contexto latino-americano favorece a MP $\mathrm{n}^{\circ} 746$, emoldurando culturalmente o "desmonte da educação pública". Contudo, cabe lembrar que nos dois últimos anos a Organização das Nações Unidas (ONU) emitiu pareceres contrários à privatização da educação em vinte países, dentre os quais o Brasil (CROSO, 2016). Isso significa o poder de uma organização internacional externa que pode apoiar o movimento protagonista de estudantes. Como diz Croso (2016, p. 8): "É a mobilização que nos dá esperança, em especial a dos estudantes que vêm resistindo e devolvendo o sentido público da educação".

\section{Considerações finais}

Debatemos aqui uma concepção social de linguagem, em relação ao mundo contemporâneo, e o protagonismo da linguagem na diversidade de agentes sociais, em face de abusos de poder dos governos estaduais e federal. Considerando a prática social nos textos analisados, nota-se um movimento entre as instituições e a população, indicando a necessidade de ouvi-la e atender suas demandas.

O protagonismo da linguagem e dos textos foi debatido à luz de dois textos sobre a ocupação de escolas no país. A análise de ideologias linguísticas fundamenta o protagonismo, na oposição examinada entre o discurso da violência e o emancipatório. Defendemos aqui uma teoria do

\footnotetext{
${ }^{5}$ Itálicos no original. CROSO, C. A MP n. 746 no contexto de privatização da educação regional e global. Le Monde Diplomatique Brasil, nov. 2016, p. 8.
} 
protagonismo da linguagem, que deverá ser pesquisado em outros trabalhos. O desenvolvimento dessa teoria, além de necessário, no sentido de dar sustentação a um discurso político crítico, significa um avanço no debate sobre a teoria social da linguagem. É por causa dos atos mobilizadores dos agentes sociais que a linguagem e os textos são protagonistas. Certamente, é preciso reconhecer o protagonismo das forças conservadoras de nossa sociedade no projeto de elites intelectuais e econômicas, que sempre foi o baluarte visível da manutenção do status quo. Os defensores desse projeto descartam as demandas da população, demandas por equidade nas relações sociais e por uma educação de qualidade, e que se distinguem dos interesses das elites favoráveis ao ideário neoliberal.

A dimensão discursiva da prática social apresenta um protagonismo da linguagem tanto no título do primeiro texto ("garotas em luta"), quanto em vários outros pontos (por exemplo, "meninas que conduzem [...], organizam [...], promovem [...] e vão para rua gritar”). Há um movimento textual intenso, pois as participantes da ocupação são ouvidas e destacadas.

As identidades sociais construídas nesse texto situam-se claramente em um campo de resistência. No entanto, é preciso registrar que o macrocontexto, principalmente do segundo texto, é uma sociedade capitalista neoliberal que não visa ao desenvolvimento das pessoas, mas à criação de condições e agentes sociais que promovam o lucro e a livre acumulação de capital, de acordo com o espírito do capitalismo. Portanto, o macrocenário do protagonismo da linguagem e dos textos inclui discursos hegemônicos e repressores (a polícia, o Estado) e discursos associados à resistência das forças sociais ligadas à construção de relações de igualdade e de promoção de direitos.

\section{Referências}

ARCHER, M. Making our way through the world. Cambridge: Cambridge University Press, 2007.

AUSTIN, J. L. How to do things with words. Oxford: Oxford University Press, 1962. BAGNO, M. Do galego ao brasileiro, passando pelo português: crioulização e ideologias linguísticas. In: MOITA LOPES, L. P. (Org.). O português no século XXI: cenário geopolítico e sociolinguístico. São Paulo: Parábola, 2013. p. 319-338.

BAKHTIN, M. Marxismo e filosofia da linguagem. Trad. de Michel Lahud e Yara Frateschi Vieira. São Paulo: Hucitec, 1979. 
BARTON, D. Understanding textual practices in a changing world. In: BAYNHAM, M.; PRINSLOO, M. (Org.). The future of literacy studies. Houndmills: Palgrave Macmillan, 2009. p. 38-53.

BARTON, D.; PADMORE, S. Roles, networks and values in everyday writing. In: BARTON, D.; IVANIC, R. (Ed.). Writing in the community. Thousand Oaks: Sage, 1991. p. 58-77.

BARTON, D.; HAMILTON, M. Literacy, reification and the dynamics of social interaction. In: BARTON, D.; TUSTING, K. (Ed.). Beyond communities of practice: language, power and social context. Cambridge: Cambridge University Press, 2005. p. 14-35.

BARTON, D.; PAPEN, U. (Org.). The anthropology of writing: understanding textuallymediated worlds. London: Continuum, 2010.

BHASKAR, R. Scientific realism and human emancipation. London: Verso, 1986.

BLOCK, D. Unpicking agency in sociolinguistic research with migrants. In: GARDNER, S.; MARTIN-JONES, M. Multilingualism, discourse and ethnography. Abingdon: Routledge, 2012. p. 47-60.

BLOMMAERT, J. Discourse. Cambridge: Cambridge University Press, 2005.

CAMPOS, A. M.; MEDEIROS, J.; RIBEIRO, M. M. Primavera secundarista: as ocupações se espalham... E as estratégias de repressão também. Le Monde Diplomatique Brasil, São Paulo, p. 4, 3 nov. 2016.

CHIAPELLO, E.; FAIRCLOUGH, N. Understanding the new management ideology: a transdisciplinary contribution from critical discourse analysis and new sociology of capitalism. Discourse \& Society, Thousand Oaks, v. 13, n. 2, p. 185-208, 2002.

CHOULIARAKI, L.; FAIRCLOUGH, N. Discourse in late modernity: rethinking critical discourse analysis. Edinburgh: Edinburgh University Press, 1999.

COLLIER, A. Critical realism. London: Verso, 1994.

CROSO, C. A MP n. 746 no contexto de privatização da educação regional e global. Le Monde Diplomatique Brasil, São Paulo, p. 7-8, nov. 2016.

FAIRCLOUGH, N. Discurso e mudança social. Brasilia: UnB, 2001 a [2a ed. 2016].

FAIRCLOUGH, N. The dialectics of discourse. Textus, Genoa, v. XIV, n. 2, p. 231-242, 2001b.

FAIRCLOUGH, N. A dialética do discurso. In: MAGALHÃES, I. (Org.). Discursos e práticas de letramento: pesquisa etnográfica e formação de professores. Campinas: Mercado de Letras, 2012. p. 93-107. 
FAIRCLOUGH, N. Analysing discourse: textual analysis for social research. Abingdon: Routledge, 2003.

FAIRCLOUGH, N. Language and globalization. Abingdon: Routledge, 2006.

FAIRCLOUGH, N. Critical discourse analysis. 2. ed. Harlow: Pearson /Longman, 2010.

FARACO, C. A. Por uma pedagogia da variação linguística. In: CORREA, D. A. (Org.). A relevância social da linguística: linguagem, teoria e ensino. São Paulo: Parábola, 2007. p. 21-50.

FOUCAULT, M. A ordem do discurso. Trad. de Laura Fraga de Almeida Sampaio. São Paulo: Loyola, 1996.

GAL, S.; IRVINE, J. The boundaries of languages and disciplines: how ideologies construct differences. Social Research, New York, v. 62, n. 4, p. 967-1001, 1995.

GRAMSCI, A. Selections from the prison notebooks. London: Lawrence \& Wishart, 1971. GUMPERZ, J. J. (Org.). Language and social identity. Cambridge: Cambridge University Press, 1982.

HALLIDAY, M. A. K. Language as social semiotic the social interpretation of language and meaning. Baltimore: University Park Press, 1978.

HALLIDAY, M. A. K. An introduction to functional grammar. 2. ed. London: Edward Arnold, 1994.

HARVEY, D. Condição pós-moderna: uma pesquisa sobre as origens da mudança cultural. 9. ed. Trad. de Adail Ubirajara Sobral e Maria Stela Gonçalves. São Paulo: Loyola, 2000.

HARVEY, D. Justice, nature and the geography of difference. London: Blackwell, 1996.

HELD, D. et al. Global transformations: politics, economics and culture. Cambridge: Polity, 1999.

HELLER, M. Language choice, social institutions and symbolic domination. Language in Society, Cambridge, v. 24, n. 3, p. 373-405, 1995.

HYMES, D. H. Models of the interaction of language and social life. In: GUMPERZ, J.; HYMES, D. (Org.). Directions in sociolinguistics: the ethnography of communication. New York: Holt, Rinehart and Winston, 1972. p. 35-71.

JESSOP, B. The crisis of the national spatio-temporal fix and the ecological dominance of globalising capitalism. International Journal of Urban and Regional Research, Hoboken, v. 24, n. 2, p. 323-360, 2000.

KRESS, G. Multimodality. Abingdon: Routledge, 2010.

KRESS, G.; VAN LEEUWEN, T. Reading images: the grammar of visual design. Abingdon: Routledge, 1996. 
LEÃO, R. F. Reforma autoritária e extemporânea do Ensino Médio: trabalhadores em educação resistem. Le Monde Diplomatique Brasil, São Paulo, nov. 2016, p. 5.

MAGALHÃES, I. Análisis crítico del discurso e ideología de género em la Constitución brasileña. In: BERARDI, L. (Org.). Análisis crítico del discurso: perspectivas latinoamericanas. Santiago: Frasis, 2003. p. 17-50.

MAGALHÃES, I. Gênero e discurso no Brasil. Discurso \& Sociedad, Madrid, v. 3, n. 4, p. 714-737, 2009. Disponível em: $<$ https://goo.gl/5d2WoP $>$. Acesso em: 6 jan. 2017.

MAGALHÃES, I. Análise de discurso crítica: questões e perspectivas para a América Latina. In: RESENDE, V. de M.; PEREIRA, F. H. (Org.). Práticas socioculturais e discurso: debates transdisciplinares. Covilhã: LabCom Books, 2010. p. 9-28.

MAGALHÃES, I. Agenciação e exclusão no atendimento educacional a estudantes com deficiência. In: PINTO, J. P.; FABRÍCIO, B. F. (Org.). Exclusão social e microrresistências: a centralidade das práticas discursivo-identitárias. Goiânia: Cânone Editorial, 2013, p. 355-368.

MAGALHÃES, I.; MARTINS, A. R.; RESENDE, V. M. Análise de discurso crítica: um método de pesquisa qualitativa. Brasília: UnB, 2017.

MARTIN-JONES, M.; GARDNER, S. Introduction: multilingualism, discourse and ethnography. In: GARDNER, S.; MARTIN-JONES, M. (Org.). Multilingualism, discourse and ethnography. Abingdon: Routledge, 2012. p. 1-15.

MARTINS, A. R. N. A polêmica construida: racismo e discurso da imprensa sobre a política de cotas para negros. 2011. 210 f. Tese (Doutorado em Linguística) Faculdade de Brasília, Brasília: Senado Federal, 2011.

MODELLI, L. Escolas ocupadas: garotas em luta. Caros Amigos, São Paulo, jan. 2016, p. 38-39.

MOITA LOPES, L. P. Ideologia linguística: como construir discursivamente o português no século XXI. In: MOITA LOPES, L. P. (Org.). O português no século XXI: cenário geopolítico e sociolinguístico. São Paulo: Parábola, 2013. p. 18-52.

PENNYCOOK, A. Critical applied linguistics: a critical introduction. Mahwah, NJ: Lawrence Erlbaum, 2001.

PENNYCOOK, A. Language and mobility: unexpected places. Bristol: Multilingual Matters, 2012.

RAJAGOPALAN, K. Por uma linguística crítica: linguagem, identidade e a questão ética. São Paulo: Parábola, 2003.

RAMALHO, V.; RESENDE, V. M. Análise de discurso (para a) crítica. Campinas: Pontes, 2011. 
ROBERGE, P. T. The ideological profile of afrikaans historical linguistics. In: JOSEPH, J. E.; TAYLOR, T. J. (Org.). Ideologies of language. Abingdon: Routledge, 1990. p. 131-149.

RODRIGUES JÚNIOR, J. M. Letramento de professores de inglês em formação: novas perspectivas? 2015. 337 f. Tese (Doutorado em Linguística) - Universidade Federal do Ceará, Fortaleza, 2015.

SCHIEFFELIN, B. B.; WOOLARD, K. A.; KROSKRITY, P. V. (Org.). Language ideologies: practice and theory. Oxford: Oxford University Press, 1998.

SMITH, D. Texts, facts and femininities: exploring relations of ruling. Abingdon: Routledge, 1990.

TOMLINSON, J. Globalization and culture. Cambridge: Polity, 1999.

VAN DIJK, T. A. Discurso e contexto: uma abordagem sociocognitiva. Trad. de Rodolfo Ilari. São Paulo: Contexto, 2012.

VERTOVEC, S. Super-diversity and its implications. Ethnic and Racial Studies, Abingdon, v. 30, n. 6, p. 1024-1054, 2007.

WENGER, E. Communities of practice: learning, meaning and identity. Cambridge: Cambridge University Press, 1998. 